\title{
The Effectiveness of Existing Risk Warning Systems to Gain Organizational Resilience: An Empirical Analysis of the Potential Risks and Vulnerability of Companies in the Mobility Industry
}

\author{
Esther Sophie Heckmann \\ Catholic University of Murcia, UCAM International Ph.D. School (EIDUCAM), \\ Ciencias Sociales, Murcia, Spain
}

\section{ABSTRACT}

Companies in the mobility industry have different and special risk management systems that strengthen their organizational resilience. Considering the new ISO standard on organizational resilience and security, developed and published in 2017, this paper looks at the current vulnerability of companies in the mobility industry. This paper presents different and special risk warning systems and uses empirical data to assess their effectiveness in the context of typical risks in this industry.

The risks were based on a literature review of risk factors in the mobility industry. This was followed by a survey and evaluation of these risks and warning systems. The data sample consists of almost 200 survey respondents. With the help of the scientific analysis software MAXQDA the data is analyzed. The results show a significant correlation between typical risks and their occurrence in the mobility industry. The effectiveness of existing risk warning system can be confirmed for large companies, but not for smaller ones.

Due to the timeliness of the topic and the new ISO standard for security and resilience published in 2017, there is no evaluation of the risks and systems in this industry so far. The study finishes with an identification of research gaps and a recommendation for further research as well as research limitations.

Keywords: Organizational Resilience; Risk warning systems; ISO/ OHSAS; Risk management system (RMS/ IMS/SMS); MAXQDA; 


\section{INTERNATIONAL CONFERENCE ON BUSINESS, MANAGEMENT AND FINANCE}

\section{UNITED KINGDOM | LONDON | March 7-9,2019}

\section{Introduction}

The average lifespan of a company decreased in the last 60 years. The mobility industry is dominated by few and long-established companies in the market. However, this industry has been repeatedly accompanied by corporate crises over the past ten years. The closure of air carriers Hamburg International 2010 and Airberlin 2017 are examples of corporate closures due to poor or late crisis management.

To gain lifelong success and growth it is important for a company to build up organizational resilience. But how can a company build resilience and what does organizational resilience means regarding company crises? In 2017 the ISO published a definition and a recommendation for attributes and factors for organizational resilience and security. This new standard has not been put into practice nor it has been evaluated regarding the existing Risk Warning Systems.

Companies need an existing and effective risk warning system. This paper takes the mobility industry into consideration and analyses the main driver for company crises. Moreover, the paper illustrates the vulnerability of this special industry. The mobility industry exists of stable and long-established market participants. The market is growing and competition brings the existing and established mobility providers into movement. New entrants have entered the market within the last years and are successfully but slow growing.

The purpose of this paper is presenting the results of an empirical survey on the existing risks for providers in this industry and moreover evaluating the effectiveness of the existing Risk Warning System. The background for this investigation is that so far for the mobility industry still no investigations of specific risks exists. Therefore, this paper raises the research question:

\section{What kind of crises appears in the mobility industry? Are existing risk warning systems effective in creating organizational resilience?}

The paper is structured as follows. First, the theoretical background and the most important research results on organizational resilience are presented. This is followed by a derivation of hypotheses based on the presented questions. Then the research design is presented. In the empirical part, the typical corporate risks are tested in the context of the mobility industry. In a second step, a survey will examine the identified typical risks of the mobility industry and examine the effectiveness of existing risk warning systems. The results are presented in detail with the empirical quantitative proofs in order to conclusively highlight the research gaps, limitations of this paper and future questions.

\section{Research Status and Hypothesis}

Research into organizational resilience is new. Therefore, there is no valid definition of organizational resilience. 


\section{INTERNATIONAL CONFERENCE ON BUSINESS, MANAGEMENT AND FINANCE}

\section{UNITED KINGDOM | LONDON | March 7-9,2019}

However, there is a shift towards organizational resilience derived from the Berkley Group study concerning the term of high-reliability organizations (HROs). The HRO organizations need to be better prepared than other organizations in times of crises. For example, nuclear power plants and hospitals need emergency plans, because the reaction time needs to be short. The Berkeley group has identified principles that allow HROs to remain operational even in critical situations.

Weick generalizes the principles of HROs in their monograph, Managing the Unexpected (Weick, 2007). He identified five principles: creating a diversity of perspectives, creating sensitivity, pursuing resilience, introducing a culture of mistakes, and providing external support in decision-making.

McManus (2007) has defined organizational resilience based on empirical research.

He has demonstrated three factors: situation awareness, management concerning Keystone vulnerabilities and adaptive capacity. For his study, the researcher developed resilience profiles of companies and surveyed companies through interviews and questionnaires.

In his monograph entitled The Resilient Enterprise Yossi Sheffi (2012) presented a case study on the companies Nokia, Ericsson and GM to illustrate how these companies could fail due to disruption. His background includes the U.S. attack on 09/11/2001 and the environmental disaster, Hurricane Katrina. As a result, he was able to build a vulnerability map. He shows how a reduced vulnerability can emerge for a company. The steps include organizing for action, assessing vulnerabilities, reducing the likelihood of disruptions, collaborating on security, building in redundancies, designing resilient supply chains and investing in training and culture. Sheffi summarizes, that Flexibility is the key factor for economic success.

The onset of organizational resilience in US science not only triggered the attack on the World Trade Center, but also the 2008 financial crisis. Nassim Taleb in his book The Black Swan came up with the theory that the companies do not know what our business will experience tomorrow and that they are at great risk if they recognize the disruptive forces too late.

A standard for organizational resilience and security was published by the International Organization for Standardization in the year 2017, defining resilience as follows: "Organizational resilience is the ability of an organization to absorb and adapt in a changing environment to enable it to deliver its objectives and to survive and prosper. More resilient organizations can anticipate and respond to threats and opportunities, arising from sudden or gradual changes in their internal and external context. Enhancing resilience can be a strategic organizational goal, and is the outcome of good business practice and effectively managing risk."

Following the publication of the ISO standard, which aims to help companies develop, implement and evaluate organizational resilience, there is still a lack of further studies that verify the accuracy of the elements of the ISO standard. 


\section{INTERNATIONAL CONFERENCE ON BUSINESS, MANAGEMENT AND FINANCE}

\section{UNITED KINGDOM | LONDON | March 7-9,2019}

There are no studies on existing industry-specific risks for the mobility industry. In addition, there is no evaluation of existing risk management systems.

To answer the research question, hypotheses were formed:

Hypotheses 1: There are no differences in the risks of the aerospace mobility industry and the railway mobility industry.

Hypotheses 2: The mobility industry already protects itself against risks by implementing the new ISO Standard on organizational resilience and security and their nine attributes.

Hypotheses 3: Risk prevention is already been done and that risk management systems are in place and effective.

\section{Research Design}

For the complex issues, two quantitative analysis approaches were chosen. Both analyses are conducted using MAXQDA Analytics Pro version 18.0.1. (Kuckartz, 2014).

In the first step of the analysis the company reports, highlighting the numbers, data, facts for their stakeholders, investors and customers, were used to extract the most important risks mentioned by the companies.

To limit the sample mobility providers were taken who offer their services on the German mobility market. The providers limit themselves to the transport of persons instead of goods and come primarily from the railway and aviation mobility.

The selection of companies was based on the approach that the selected companies operate in Germany. There was no distinction between small and large companies. In addition, the age of the company played no relevant role. The public reports are from the business years 2016 to 2018, with the majority reported in the financial year 2017. In principle, the three financial years under review can be defined as stable and inconspicuous years in terms of general economic activity in the European mobility industry. Only one supplier, Airberlin, which had to file for bankruptcy in 2017, was in crisis mode. All other companies have achieved economic growth in the three years under review. When selecting the companies, care was taken to focus on a similar number of companies from the railway sector and airlines. Car-sharing and mobility-ondemand providers, which are primarily in the automotive sector, have been explicitly excluded, as they are new market players that are re-offering mobility in its proven form. This procedure allows comparability among the mobility providers of the railway and aviation sectors.

The company reports were uploaded to the Maxqda analysis software. On the basis of crisis management terms, the reports were frequency-counted. 


\section{INTERNATIONAL CONFERENCE ON BUSINESS, MANAGEMENT AND FINANCE}

UNITED KINGDOM | LONDON | March 7-9,2019

The reports have a similar number of pages, but it can be seen that the reports of the larger companies tend to include a higher number of report pages, which could lead to a trend towards a higher number of codings. This could not be confirmed as it is shown in table 1.

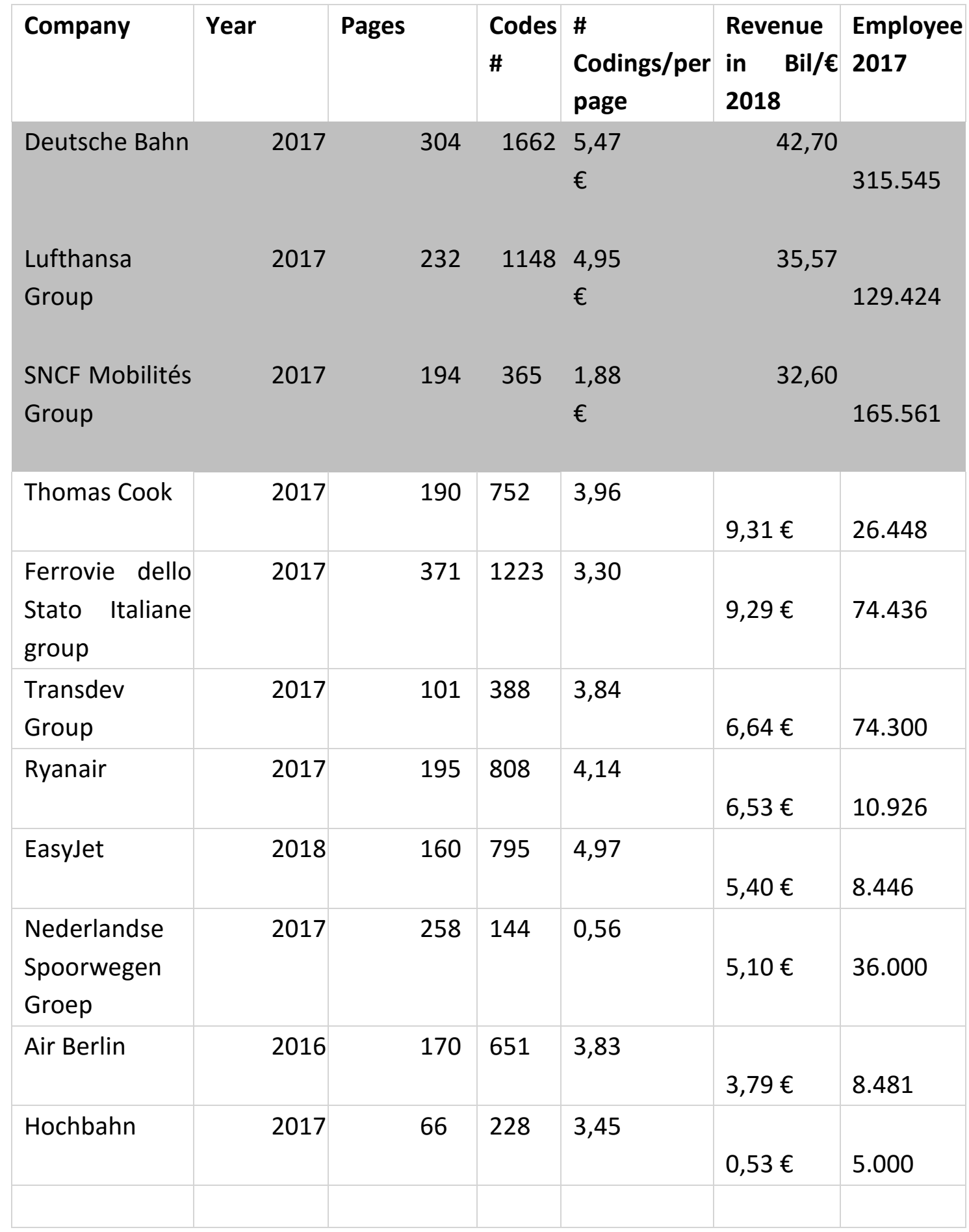


INTERNATIONAL CONFERENCE ON BUSINESS, MANAGEMENT AND FINANCE

UNITED KINGDOM | LONDON | March 7-9, 2019

\begin{tabular}{|l|l|l|l|l|l|l|}
\hline Total \# & & 2241 & 8164 & & & \\
\hline Mean & 2017 & 203 & 742 & 3,66 & & \\
\hline
\end{tabular}

Table 1 - Codings in relation to Company Size

Eleven published company reports were used for the analysis. The reports are publicly available annual financial statements published in the form of integrated reports, annual reports, financial reports, financial statements, sustainability reports and management reports. The reports are accessible online and intended for the target group of the interested public, investors, owners, stakeholders, competitors and customers. The data are due to the recipient groups and intention of the creators in their value as secondary data since they were not collected from the author.

The sample of the survey consists of 195 survey respondents. The survey participants work in the mobility industry, in the management or as employees. The participants have been contacted and asked for participation through the business network Xing and distributed in groups relating to the mobility industry. The focus group is a member of the railway, the airway, the platform providers and the automotive mobility industry. The survey was preceded by a pretest. After improving and clarifying the questions, the survey was online for six weeks. The first block queried the statistical data of the respondents. This included, among other things, the position in the company, the size of the company's turnover, the number of employees in the company. In the second part, the existing risks of the mobility industry were rated on a scale in the range of 1 to 5 , with 5 being the strongest. In the next step, the effectiveness of the existing risk warning systems was tested on a scale from 1 to 101 . On the one hand, existing certifications, such as the ISO standard or existing risk management systems were queried. Respondents were able to indicate in a separate box whether a risk warning system exists or not. The participants could deposit their e-mail addresses if they were interested in the results of the survey. The survey data was transferred to the analysis program and evaluated.

The data analysis complies with the scientific standards of validity, reliability and objectivity. In particular, in the case of validity, the way in which it is measured and what should be measured in order to ensure the validity of the results. Reliability ensured that repeated measurements would yield the same results to meet the criterion of accuracy and reliability of the measurement. Because objectivity was reflected, whether the researcher influenced the measurement results to ensure the criterion of independence from the researcher.

\section{Results and Discussion}

The first hypothesis, that there are different risks in aviation mobility compared to the railway 


\section{INTERNATIONAL CONFERENCE ON BUSINESS, MANAGEMENT AND FINANCE}

\section{UNITED KINGDOM | LONDON | March 7-9,2019}

mobility will be examined. In the first step of the analysis of the company reports, the typical risks of the mobility industry were identified. Nine Risk factors are specific to the mobility industry.

The strongest risk factor is the changing customer expectations which are valid and important or all of the mobility service providers. However, there is a slight tendency for dependency on customers to be more pronounced within the aviation industry than for railway providers. Instead, the factor of changing mobility demand is of greater importance to railway companies than to the aviation industry. The big megatrends, such as digitization, pose a greater risk to rail companies than to the aviation industry.

In addition, dependence on suppliers is stronger for the railway industry than for airlines. The relationship may be related to the number of suppliers on the market, especially in the railway sector, which is lower than in the aviation industry. No difference between the mobility providers can be seen at the following points in the following risk factors: Fault of Management, Union Strike, Fluctuation of employees, don't live corporate values, loss of know-how, war for talents (Figure 1).

The first hypothesis that there are no differences in the risks of the aerospace mobility industry and the railway mobility industry can be rejected.

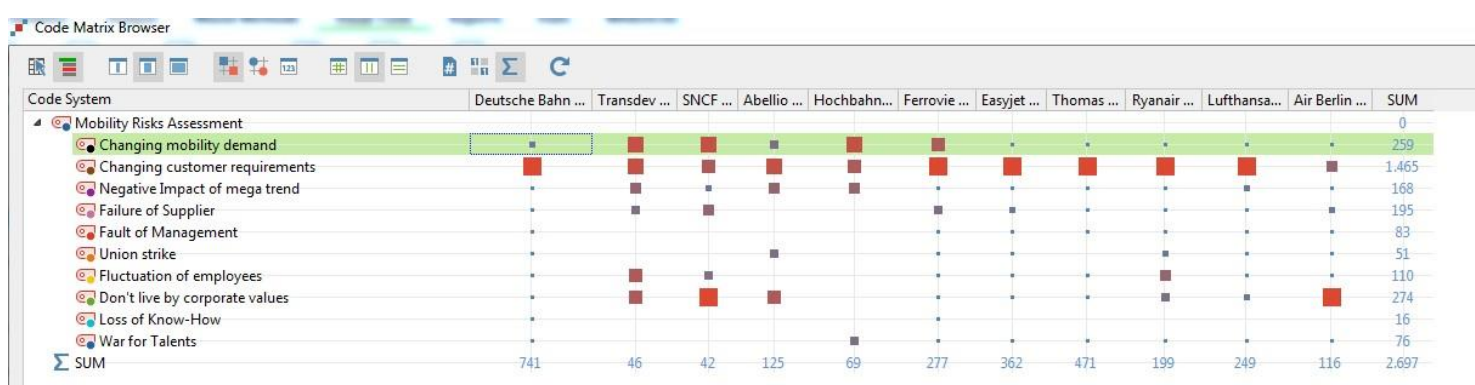

Figure 1 - Maxqda Analysis of the typical risks in the mobility industry.

The results were tested in the second step by a survey and are shown in the average compared to the minimum and maximum value. The 195 respondents from the mobility industry give a different assessment of the risks. The risk factors of the influences of megatrends, the loss of know-how, the war for talents, as well as errors of the management are assessed much more strongly, as in the reports of the enterprises becomes visible. It's not surprising that management's mistakes in a report written primarily by management are rated lower than in a survey of employees and management members. It is confirmed that the impact of Union strikes is also rated much lower than the risk in the survey, as in the company reports. The influences of changing customer requirements and changing mobility demand are confirmed (Figure 2). 
INTERNATIONAL CONFERENCE ON BUSINESS, MANAGEMENT AND FINANCE

UNITED KINGDOM | LONDON | March 7-9,2019

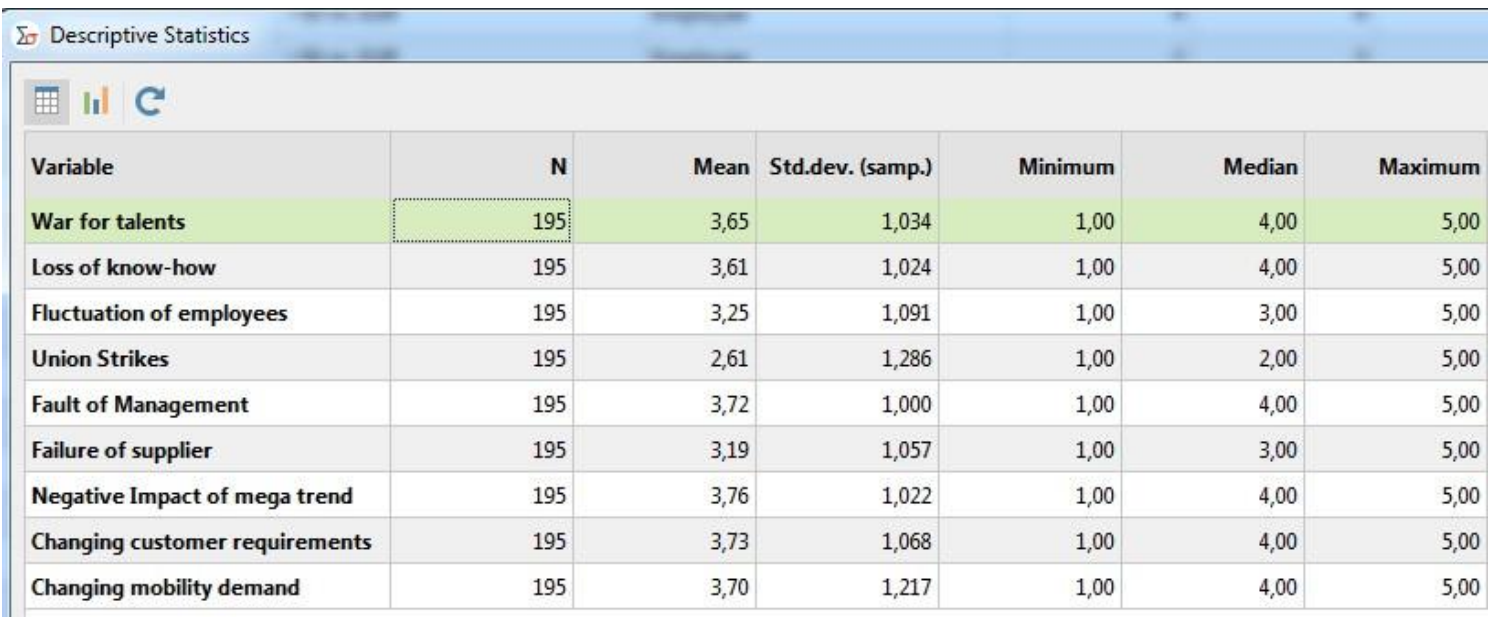

Figure 2 - Assesment of the risks in Maxqda Stats.

In a second step, to test the vulnerability of the mobility industry and the effectiveness of risk management systems for the production of organizational resilience, a review of the resilience factors will be carried out.

The nine attributes of the ISO Standard on Organizational Resilience and Security, published in 2017 , were examined in the eleven company reports. The attributes were counted by a frequency counting of the terms in the enterprise reports. Particularly noteworthy is the number of appearing attributes and in addition that these appeared in almost all reports of the mobility companies (Figure 3).

\begin{tabular}{|c|c|c|c|c|}
\hline 0 & 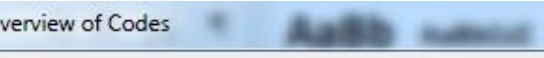 & 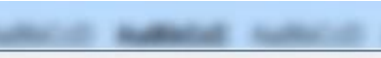 & 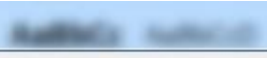 & +2 \\
\hline \multicolumn{5}{|l|}{ All } \\
\hline \multicolumn{5}{|l|}{ ๑ } \\
\hline & Code & Coded segments of all documents & $\%$ Coded segments ... & Documents \\
\hline 0 & Ability to anticipate and managing change & 2.604 & 31,90 & 11 \\
\hline - & Supporting continual improvement & 228 & 2,79 & 9 \\
\hline ? & Development and coordination of management disciplines & 2.223 & 27,23 & 10 \\
\hline - & Availability of resources & 228 & 2,79 & 11 \\
\hline - & Shared information and knowledge & 1.082 & 13,25 & 8 \\
\hline P & A culture supportive of organizational resilience & 98 & 1,20 & 7 \\
\hline ? & Effective and empowered leadership & 83 & 1,02 & 7 \\
\hline ? & Understanding and influencing context & 97 & 1,19 & 9 \\
\hline ? & Shared vision and clarity of purpose & 1.521 & 18,63 & 10 \\
\hline
\end{tabular}

Figure 3- Overview of coded segments.

For the mobility providers, there is a high frequency in the attribute ability to anticipate and manage change as well as in the attribute development and coordination of management discipline. The attributes shared vision and clarity of purpose and shared information and knowledge are also well received in corporate reports (Figure

4). 

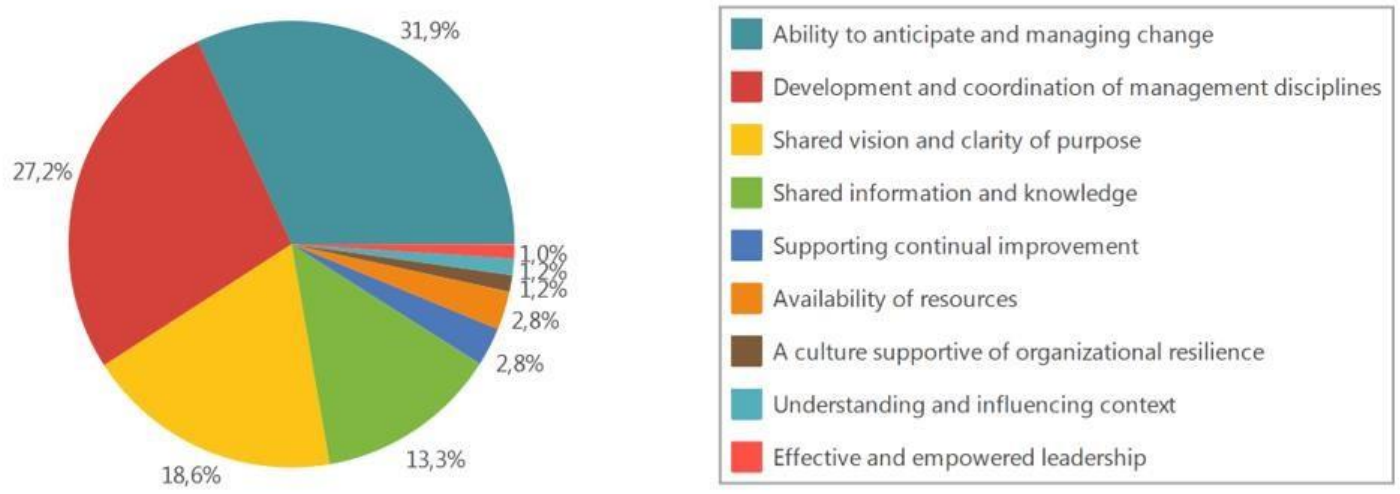

Figure 4 - Testing the ISO Norm on the corporate Reports.

Comparing the presence of the ISO attributes of the railway undertakings with those of the airlines, the only difference is the attribute shared vision and clarity of purpose and shared information and knowledge.

The importance of the attribute shared vision and clarity of purpose for the aviation industry can be explained by the stronger competitive orientation and lower monopoly position than in the railway industry. In return, the railway companies are sensitized and work proactively on the subject of shared information and knowledge (Table 2).

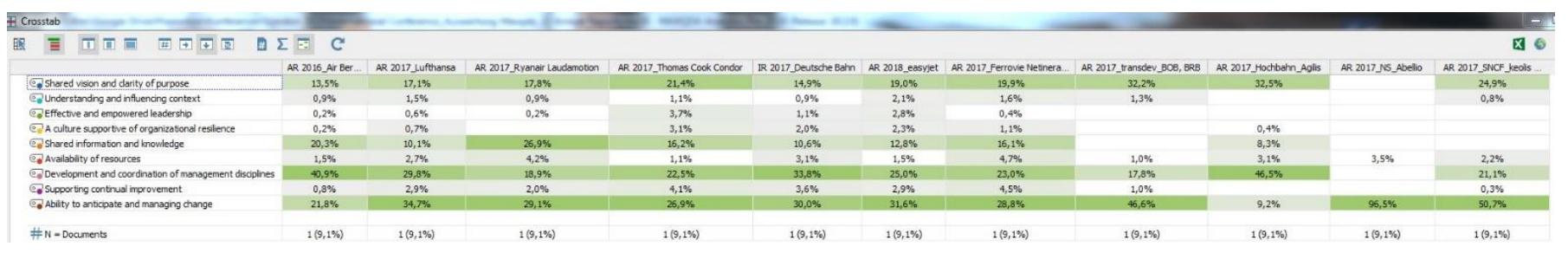

Table 2 - ISO attributes compared railroad to air transport mobility.

It can be seen that the mobility companies have already responded to many of the important attributes of the ISO standard and identified them as proactive risks and proactively strengthen their attributes. However, neglected and unrecognized are some of the important attributes that the ISO standard recommends from companies stepping up as a risk warning system. The understanding of the influential context, the effective and empowered leadership, the culture supportive of organizational resilience, the availability of resources and the support of continual improvement are very important but not yet recognized preventive attributes. The concept of organizational resilience does not seem to have come to the consciousness of mobility companies in the context of risk prevention and risk warning systems.

The second hypothesis the mobility industry already protects itself against risks by implementing the new ISO Standard on organizational resilience and security and their nine attributes cannot be rejected. 


\section{INTERNATIONAL CONFERENCE ON BUSINESS, MANAGEMENT AND FINANCE}

\section{UNITED KINGDOM | LONDON | March 7-9,2019}

The survey also asked if and which risk management systems exist in the company, for example, whether certification or risk management systems are available. In addition, on a scale of 1 to 101, it was asked to what extent the respondents rated the existing system as effective for prevention and in crisis situations.

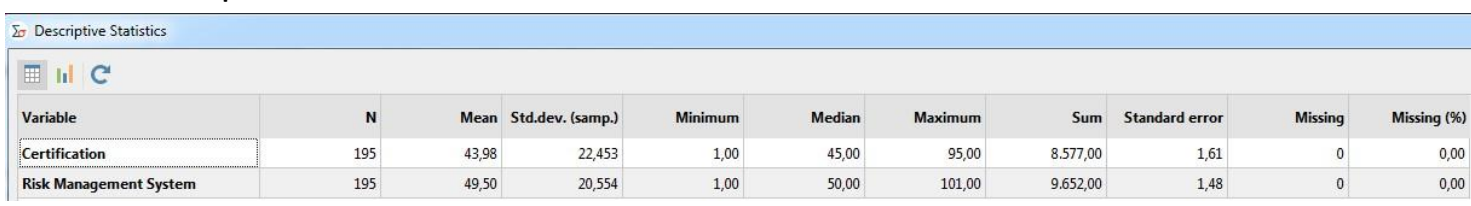

Table 3 - Effectiveness of existing risk warning systems within mobility companies.

The evaluation of the existing risk systems does not show the range of what possibly still exists in risk management systems in the mobility companies. This would require an open poll this. All 195 respondents answer the question (Table 3). The issue of certification as a risk goods system showed an average of 94 points out of 44 points and the risk management systems an average of 50 points. Thus, the effectiveness of a risk warning system over existing certifications such as ISO, OSAS, SMS or IMS is considered to be more effective.

Thus, the hypothesis that risk prevention is already been done and that risk management systems are in place and effective cannot be rejected.

From the investigation, there are research gaps that are not answered yet. The nine specific factors for the mobility industry would have to be contrasted with other industries. The results should be reflected in the context of the political, social and economic situations prevailing from 2016 to 2018. In addition, it would be important to interpret the strategy presented in the company's report against the background of the results. How is the ISO standard received in companies and how can organizational resilience be measured in companies? These are some of the questions that are still unanswered.

The evaluations are limited in their validity and also not transferable to other mobility providers z.b. from the automotive industry. The evaluation of the existing risk systems does not show the range of what possibly still exists in risk management systems in the mobility companies. This would require an open poll.

\section{Refrences}

Air Berlin. (2017). 2016 Annual Report. Retrieved from http://www.annualreports.com/HostedData/AnnualReports/PDF/OTC_AIBEF_2 016.pdf Deutsche Bahn. (2018). 2017 Integrated Report. Retrieved from https://www1.deutschebahn.com/resource/blob/1639240/4bcaf98f54cf3ba4c84c83d4e0ae a926/ib2017_dbkonzern_en-data.pd Easyyet plc. (2019). Annual Report and Accounts 2018. Retrieved from 
INTERNATIONAL CONFERENCE ON BUSINESS, MANAGEMENT AND FINANCE

UNITED KINGDOM | LONDON | March 7-9,2019

http://corporate.easyjet.com/ /media/Files/E/Easyjet/pdf/investors/resultscentre/2018/20 18-annual-report-and-accounts.pdf

Ferrovie dello Stato Italiane group. (2018). 2017 Annual Report. Retrieved from

https://www.fsitaliane.it/content/dam/fsitaliane/en/Documents/investorrelations/financial -statements/2017_Annual_report_FS.pdf

Hochbahn. (2018). Annual Report 2017. Retrieved from

https://www.hochbahn.de/hochbahn/wcm/connect/de/abe02f2d-6787-4eb6-82ec-

6f22d073101f/180615_hbn_ub17_pflicht_e_save.pdf?MOD=AJPERES\&CACHEI

D=ROOTWORKSPACE.Z18_JH8I1JCOL05M10AEB6TSP430A1-abe02f2d-6787-

4eb6-82ec-6f22d073101f-mgSH2U-

ISO 22316:2017. (2017). Security and resilience - Organizational resilience - Principles and attributes.

Kuckartz, U. (2014). Qualitative Text Analysis. A Guide to Methods, Practice and Using Software. Sage Publications Ltd., 2014.

Lufthansa Group. (2018). Annual Report 2017. Retrieved from

https://investorrelations.lufthansagroup.com/fileadmin/downloads/en/financialreports/an

nual-reports/LH-AR-2017-e.pdf

McManus, S., Seville, E., Brunsdon, D. \& Vargo, J. (2007). Resilience Management.

Resilient Organisations, 01, 1-79. Retrieved February 15, 2007.

Nederlandse Spoorwegen Groep. (2018). NS Annual Report 2017. Retrieved from

https://www.nsjaarverslag.nl/FbContent.ashx/pub_1000/downloads/v1804191

11054/NS_annualreport_2017.pdf

Ryanair. (2018). Ryanair Fiscal Year 2017 Annual Report. Retrieved from

https://investor.ryanair.com/wp-content/uploads/2017/07/Ryanair-FY2017Annual-

Report.pdf

Sheffi, Y. (2007). The Resilient Enterprise. Overcoming Vulnerability for Competitive Advantage. Cambridge: MIT Press.

SNCF Mobilités Group. (2018). Management Report on corporate Goverance and consolidated financial statements.

Retrieved from

https://www.sncf.com/sncv1/ressources/reports/sncf_mobilites_2017_financial_report_0.p df

Taleb, N. N. (2010) The Black Swan: The Impact of the Highly Improbable Fragility. New York: Random House US.

Thomas Cook. (2018). Annual Report \& Accounts 2017. Retrieved from https://www.thomascookgroup.com/investors/insight_external_assest/Thoma s-Cook-AR2017.pdf 


\section{ICBNF}

INTERNATIONAL CONFERENCE ON BUSINESS, MANAGEMENT AND FINANCE

UNITED KINGDOM | LONDON | March 7-9,2019

Transdev. (2018). 2017 Financial Report. Retrieved from https://www.transdev.com/wpcontent/uploads/2018/06/58fc9f6-3637Financial-report-2017.pdf

Weick, K. E. (2007). Managing the unexpected: Resilient performance in an age of uncertainty. San Francisco, Calif.: Jossey-Bass. 